\title{
An evaluation of the key-word technique for the acquisition of Korean vocabulary by military personnel
}

\author{
DOUGLAS GRIFFITH \\ Army Research Institute Field Unit, Fort Hood, Texas 76544
}

\begin{abstract}
Sixty Army enlisted personnel representing high, medium, and low ranges of general technical (GT) aptitude learned the correct translations for a list of 15 Korean vocabulary words. Half the personnel in each group were instructed to use a mnemotechnic, the key-word technique, whereas the remaining personnel served as a standard learning control. A self-paced learning procedure was employed with number correct on the final trial, total study time, and study efficiency as the primary criterion measures. Although learning was found to be a positive function of GT aptitude, the key-word technique proved effective for all groups. Implications are discussed.
\end{abstract}

The present experiment addresses two issues. The first concerns the general utility of mnemotechnics for military personnel. An earlier experiment (Griffith \& Actkinson, 1978) found that only personnel with general technical (GT) aptitude scores of 110 or higher were able to use a one-bun rhyme mnemonic to advantage. As the GT test has an empirical mean of 100 and a standard deviation of 20 , the group that was able to use the mnemotechnic successfully closely resembled college students in mental aptitude. A conjecture regarding the failure of personnel with moderate and low GT aptitudes to use the mnemotechnic to advantage was, quite simply, that the $8 \mathrm{sec}$ provided each item was insufficient. Perhaps if the learning were unpaced, they could successfully employ the mnemotechnic.

The second issue concerns the utility of a specific mnemotechnic, the key-word technique, for military personnel. The key-word method is a mnemotechnic for vocabulary acquisition that consists of two steps. The first step involves the creation of a key word based on the sound of the to-be-acquired item to serve as an acoustic link. Take, for example, the Korean term for airplane hangar, "Kyok nap Ko." Here, the key word could be "nap." The second step involves associating the key word "nap" to the meaning, airplane hangar, by forming a mental visual image of someone taking a nap in an airplane hangar. Later, when the term "Kyok nap Ko" is encountered, the sound "nap" will likely trigger the mental image of someone taking a nap in an airplane hangar, which should allow the retrieval of the appropriate meaning. The key-word technique has been demonstrated to be effective for college students (Atkinson \& Raugh, 1975) and for high school and elementary students (Levin, Pressley, McCormick, Miller, \& Shriberg, 1979). Prior to this research, the effectiveness of the key-word technique for military personnel of varying ranges of GT aptitude had not been studied.
Also, the range of foreign languages for which the keyword technique has been employed is limited. For example, prior to this research, the effectiveness of the key-word technique for acquiring Korean vocabulary items had not been tested. Indeed, the Korean language provides a particularly instructive case. On the one hand, there is practically no overlap of English and Korean, regarding the etymology of the vocabulary. On this account, one might expect a large advantage to the key-word technique, as it would be making an exceptionally difficult task that much easier. On the other hand, the phonetic systems of the two languages are so disparate that it might render the generation of effective acoustic links especially difficult.

\section{METHOD}

\begin{abstract}
Design and Subjects
A 2 (instructional set) by 3 (GT level) by 2 (list version) factorial design was employed. All factors were manipulated between subjects. The two levels of instructional set were the key-word vs. the control groups. The three GT levels encompassed the following ranges: 90 and below, 91-109, and 110 and above. Two different lists of 15 Korean military terms were employed to enhance the generality of the findings. A total of 60 U.S. Army enlisted personnel, 20 from each of the GT levels, were employed in the data analysis. Subjects were randomly assigned to instructional sets and list versions, with the restriction that all the cells in the design be filled at the same rate.
\end{abstract}

\section{Procedure}

Subjects were run individually. At the beginning of the session, the subject was informed that the Army Research Institute was conducting a study to determine how rapidly soldiers can learn foreign vocabulary words and that the current study involved Korean words. Both the key-word and the control groups heard 10 Korean words to familiarize them with the sound of the language. For the key-word subjects, these same 10 words were used to provide instruction in the key-word technique. They were given four examples of how a key-word 
could be employed to form an image by linking the key word to its appropriate translation. For the remaining six words, key-word subjects were supplied a key word and were asked to describe the image they formed linking the key word to the appropriate translation. Feedback was provided on their efforts. Control subjects were instructed to learn the items as best they could.

At the conclusion of this instructional phase, the experiment proper was begun. During the study phase, subjects were shown the English translations of Korean words on $3 \times 5$ in. cards as the Korean was repeated at intervals of approximately $5 \mathrm{sec}$ by the experimenter. Key words were presented in parentheses next to the translations for key-word subjects. The procedure was self-paced, and subjects indicated when they were ready to go on to the next item. After all 15 items had been presented, the test phase began. During the test phase, a Korean word was pronounced at intervals of approximately $5 \mathrm{sec}$. A given item was repeated until the subject either responded with the correct English translation or requested the next item. This procedure continued until all 15 items had been tested. If all items were responded to correctly, then the session was over. If not, both study and test phases were repeated either until all 15 items were responded to correctly or until $40 \mathrm{~min}$ had elapsed from the beginning of the first trial. Subjects were not stopped if time elapsed during a trial. Rather, if it was estimated that there was insufficient time for another trial, the session was ended. The experimenter recorded the elapsed time for each study and test phase. The cards were reshuffled before each study trial. Three different test orders were used during the test phase.

\section{RESULTS}

The four following dependent variables were employed in the data analysis: the number correct on the final trial, total study time (i.e., the study time per trial summed across an individual's trials), a derived measure, the study efficiency ratio (SER), which is the number correct on the final trial divided by the total study time, and the total test time (i.e., the recall test time per trial summed across an individual's trials). Separate univariate ANOVAs were computed on each dependent variable.

As the ANOVAs of number correct on the final trial, total study time, and the SERs reveal highly similar patterns of results, and as the SER provides the best summary of these results, only the SER ANOVA will be reported in detail. A quick inspection of Table 1 reveals both the effectiveness of the key-word technique and the positive correlation between GT level and performance. The 2 (instructional set) by 3 (GT) by 2 (list version) ANOVA corroborated this visual inspection. The alpha level used for all reported tests was .05, and the MSe was 46.283. The effect of instructional set indicated the clearly superior performance of the key-word group $[F(1,48)=16.49]$. The GT effect $[F(2,48)=10.94]$ reflected that study efficiency was a positive function of GT aptitude. Newman-Keuls tests indicated that all three means differed significantly from each other. There was also a list effect $[F(1,48)=$ 11.67], which was attributable to one list's being more difficult than the other (means $=15.5$ vs. 9.5). All interaction Fs were less than 1.00.

A 2 (instructional set) by 3 (GT) by 2 (list version) ANOVA of total recall test time indicated statistical
Table 1

Mean Study Efficiency Ratios (SER) as a Function of Instructional Set and General Technical Aptitude

\begin{tabular}{cccc}
\hline & \multicolumn{2}{c}{ Instructional Set } & \\
\cline { 2 - 3 } GT Range & Key Word & Control & Mean \\
\hline$\geqslant 110$ & 20.8 & 14.6 & 17.7 \\
$91-109$ & 17.1 & 7.4 & 12.2 \\
$\leqslant 90$ & 10.3 & 4.9 & 7.6 \\
Mean & 16.1 & 9.0 & \\
\hline
\end{tabular}

Note-SER = number correct on final trial divided by total study time. The table entries have been multiplied by 1,000 for ease of presentation.

significance for only GT $[\mathrm{F}(2,48)=8.34, \mathrm{MSe}=40,024]$. This effect was apparently attributable to the high-GT group's requiring less time than the moderate- or low-GT groups (767 sec vs. $994 \mathrm{sec}$ and $989 \mathrm{sec}$, respectively).

\section{DISCUSSION}

The present results clearly show that military personnel, regardless of GT aptitude, are capable of using a mnemotechnic to advantage for some tasks. Apparently, the paced procedure employed in the Griffith and Actkinson (1978) experiment precluded low and moderate GT-aptitude personnel from effectively using the mnemotechnic. This finding supports the conclusion of Griffith (Note 1) that the potential of mnemonics and mnemotechnics for Army training and educational programs is significant.

The present findings also indicate the potential of the keyword technique. Korean is an especially difficult language for native speakers of English to learn, so the demonstration of the effectiveness of the key-word technique for Korean is particularly significant. Thus far, the effectiveness of the key-word technique has been demonstrated with Spanish (Raugh \& Atkinson, 1975), Russian (Atkinson \& Raugh, 1975), German (Ott, Butler, Blake, \& Ball, 1973), and now Korean. Although these formal experiments have yielded positive results, several attempts to implement the key-word technique in foreign language classes have not proven successful (e.g., Fuentes, 1976; Willerman, 1977). Researchers are beginning to investigate the reasons for the lack of success in these several instances (Levin et al., 1979).

\section{REFERENCE NOTE}

1. Griffith, D. A review of the literature on memory enhancement: The potential and relevance of mnemotechnics for military training (ARI Tech. Rep. 436). Alexandria, Va: U.S. Army Research Institute for the Behavioral and Social Sciences, 1979.

\section{REFERENCES}

Atrinson, R. G., \& Raugh, M. R. An application of the mnemonic keyword method to the acquisition of a Russian vocabulary. Journal of Experimental Psychology: Human Learning and Memory, 1975, 104, 126-133.

Fuentes, E. J. An investigation into the use of imagery and generativity in learning a foreign language vocabulary (Doctoral dissertation, Stanford University, 1976). Dissertation Abstracts International, 1976, 37, 2694A. (University Microfilms No. 7625, 997)

Griffith, D., \& Actkinson, T. R. Mental aptitude and mnemonic enhancement. Bulletin of the Psychonomic Society, 1978, 12, 347-348. 
Levin. J. R., Pressley, M., McCormick, C. B., Miller, G. E. $\&$ Shriberg, L. K. Assessing the classroom potential of the keyword method. Journal of Educational Psychology, 1979, 71, 583-594.

Ott, C. E., Butler, D. C., Blake, R. S., \& Ball, F. P. The effect of interactive-image elaboration on the acquisition of foreign language vocabulary. Language Learning, 1973, 23, 197-206.
Raugh, M. R., \& Atkinson, R. C. A mnemonic method for learning a second language vocabulary. Journal of Educational Psychology, 1975, 67, 1-16.

Wille RMAN, B. S. The effect of a keyword mnemonic on the recall of French vocabulary. Unpublished doctoral dissertation, University of Texas at Austin, 1971.

(Received for publication December 4, 1980.) 